\title{
Interconnection viability of high demand isolated area through a HVDC-VSC link
}

\author{
Juan A. Varela, Mario A. Rios
}

Department of Electrical Engineering and Electronics, School of Engineering, Universidad de los Andes, Colombia

\begin{tabular}{|c|c|}
\hline Article Info & ABSTRACT \\
\hline Article history: & \multirow{7}{*}{$\begin{array}{l}\text { Electrically isolated areas are separated by a great distance and, normally, } \\
\text { have a considerably low demand; in consequence, these are non- } \\
\text { interconnected from the main power grid or electrical national transmission } \\
\text { systems. Great distance and low demand are the reasons why an } \\
\text { interconnection project in high voltage AC is not feasible in most of these } \\
\text { cases. Nevertheless, there are some isolated areas with high power demand } \\
\text { and even though they are separated from the main grid by large distances and } \\
\text { hard terrains; however, it is still reasonable to think about an interconnection } \\
\text { project. This paper had developed a methodology that allows the evaluation } \\
\text { of viability, technically and economically, of a HDVC-VSC interconnection } \\
\text { project for great distance and high demand considering overhead and/or } \\
\text { underground DC line. The methodology was applied to a case of study in } \\
\text { Peru, based on the projected interconnection between Moyobamba and the } \\
\text { isolated area of Iquitos; showing that HVDC is a feasible alternative. }\end{array}$} \\
\hline Received Apr 2, 2020 & \\
\hline Revised Jul 26, 2020 & \\
\hline Accepted Oct 11, 2020 & \\
\hline Keywords: & \\
\hline $\begin{array}{l}\text { HVDC } \\
\text { Interconnection electric power } \\
\text { systems }\end{array}$ & \\
\hline $\begin{array}{l}\text { Transmission expansion } \\
\text { planning }\end{array}$ & \\
\hline
\end{tabular}

This is an open access article under the CC BY-SA license.

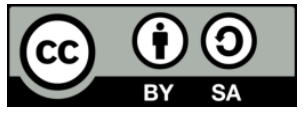

\section{Corresponding Author:}

Mario Alberto Rios

Department of Electrical Engineering and Electronics

School of Engineering, Universidad de los Andes

Carrera 1 No. 18 A-12, Bogota, Colombia

Email: mrios@uniandes.edu.co

\section{INTRODUCTION}

Nowadays, high voltage direct current (HVDC) transmission can be considered a more profitable technology than AC for some projects due to benefits such as greater power capacity transmission, reduced right of way (ROW), ease to interconnect without frequency restrictions, no need of intermediate compensation and reasonable costs achieved through technological advances on power electronics [1, 2]. Voltage source converter (VSC) technology is specially recognized for having some characteristics that allow better control over power transfer [2,3], including instantly change on direction if needed, for requiring less space (no need of extra filters like LCC technology) and for having the capacity to do black starts. For these reasons it is common to see that there is a distance, that depending on the country can vary from 500 to $800 \mathrm{~km}$, where the costs of HVDC transmission becomes the same or lower that for high voltage alternating current (HVAC) [2, 4].

In addition, new schemes of HVDC networks has been proposed in order to interconnect distant AC power systems, as islands; and renewable energy sources (wind and photovoltaic energy). Thus, there are schemes like multi-terminal DC systems [2,5] and HVDC grids [2, 4]. It may seem hard to believe, but in the $21^{\text {st }}$ century, there are still a lot of regions that are isolated from the main electrical grids [6]. Most of the time, this is synonym of poor electrical reliability, high electricity prices (fossil fuels) or no access to electricity at all. There are several reasons for these regions to remain isolated: long distances to the closest connection point, difficult or delicate terrains such as forests in between, low demands that do not justify the 
strong infrastructure investments and the low expansion potential [7]. While these reasons are valid for most of the cases, there are some other cases where regions remain isolated due to political and social factors. Thus, some authors propose the utilization of microgrids [8] or interconnected microgrids to provide the power supply for isolated areas; however, these solutions are around 10 MVA [9].

Some of these problems can be resolved through an HVDC link. The Caprivi link [10] was the first successful VSC overhead monopole link and it demonstrated that a HVDC overhead line is a very economical solution, especially for low but no negligible power. The Caprivi link was first design to transport $300 \mathrm{MW}$ through a $950 \mathrm{~km}$ monopole overhead line with the possibility to be converted in the future into a $600 \mathrm{MW}$ bipolar. Although this link interconnects to weak AC grids, the idea of an overhead monopole link can be used to interconnected isolated areas with no negligible demand and potential expansion.

Other alternative is to make long AC interconnections using series compensation based on FACTS devices, such as TCSC or SSSC [11]. However, these links normally require two high voltage AC lines demanding a big ROW and the AC system could have stability problems for interconnection of isolated areas. This paper presents a methodology for evaluating the technical and economic viability of symmetrical monopole HVDC-VSC links between main electrical grids and isolated areas with a high power demand.

Section 2 describes the research method. This methodology evaluates overhead, underground and mixed solutions from a technical and economical stand. Thus, section 2.1 presents a methodology to evaluate the cost of a monopolar HVDC link based on overhead DC design transmission lines. Section 2.2 presents an approach to estimate underground HVDC cables for monopolar configuration. Section 2.3 shows a model to estimate VSC converter station costs. Based on this methods, approaches and cost estimators, section 2.4 proposes an integrated methodology for cost estimation of an HVDC-VSC monopolar link.

Section 3 presents the results obtained when the methodology was applied to a practical case of study, this case of study is the projected $631 \mathrm{~km}$ interconnection between Moyobamba and Iquitos, at Peru. Iquitos is an isolated area of the Peruvian Amazonia that has an actual demand of nearly 100 MW expected to double in the next twenty years. In addition, there is a hydroelectric project of about $550 \mathrm{MW}$ near to Iquitos that would generate more power than own consumption of Iquitos, so this excess must be transferred somehow to the national grid $[12,13]$. Finally, section 4 discusses the conclusions and proposes further work.

\section{RESEARCH METHOD}

\subsection{Technical and economical evaluation of HVDC-VSC overhead links}

The procedure to evaluate the technical aspects of the overhead line is based on the CIGRE brochure 388 [14]. Although the brochure presents a methodology for a bipolar configuration, it can also be used to calculate the same parameters for a symmetrical monopole given the fact that it also has two conductors in the same structure with +/- some voltage, as it is proposed in this paper. The only difference between this two is over the stations but the brochure only studies the overhead line infrastructure omitting the converters.

After choosing the possible alternatives (possible DC voltage levels [15]), the first thing to do is to evaluate the capacity of the conductors in order to do a first approximation on the number of subconductors needed to transport a given power. This calculation is based on the [16] that presents equations modeling the thermal behavior of conductors. The type of conductor recommended by the brochure is ACSR. Then, it is calculated the height of the conductors and the pole spacing in order to calculate the surface gradient, which is also used as a restriction depending on the voltage and the number of conductors. A third restriction, corresponding to voltage drop was included in this methodology, proposed in this paper. With these three restrictions, the final number of conductors per alternative is chosen. Having the number of conductors per alternative is possible to calculate the pole spacing, the height and the right-of-way (ROW), given by:

$$
\begin{aligned}
& R O W=\left[(R+L+S) \sin (\theta)+d_{\text {min }}\right] \times 2+P S \\
& C_{\text {ROW }}=R O W \times L \times C_{\text {land }}
\end{aligned}
$$

where $R$ is the radius of the conductors' bundle, $L$ is the length of the insulators chain, $S$ is the sag of the conductor for a specific span, $P S$ is the pole spacing, $d_{\min }$ is the secure distance at certain voltage level and theta is the swing angle for the conductor at a specific wind condition. $C_{\text {land }}$ is the cost of the ROW land. It is important to mention that the ROW in HVDC is lower than the ROW for HVAC lines used to transmit the same power [2].

After having the dimensions of the structures, it is also possible to calculate Joule and Corona losses, $\left(L_{j}\right.$ and $\left.L_{c}\right)$ respectively, over the line. The Corona losses are calculated from an empirical equation given [14], in this equation $L_{\text {fair }}$ and $L_{\text {foul }}$ are refer to corona losses depending on the weather (80\% fair weather and $20 \%$ foul weather) as follow: 


$$
L_{c}=0.8 \times 10^{\frac{L_{\text {fair }}}{10}}+0.2 \times 10^{\frac{L_{\text {foul }}}{10}}\left[\frac{\mathrm{kW}}{\mathrm{km}}\right]
$$

In this paper, the Joule losses equation was adjusted from the one given by [14] to make it consistent with the symmetrical monopole configuration. Thus,

$$
L_{j}=2\left(\frac{P}{V}\right)^{2}\left(\frac{R_{d c}}{N}\right)\left[\frac{k W}{k m}\right]
$$

where $\mathrm{P}$ is the nominal power of the HVDC link in MW, V is the DC voltage of the monopolar configuration (in $\mathrm{kV}$ ), $R_{d c}$ is the $\mathrm{DC}$ resistance of the conductor at $20^{\circ} \mathrm{C}$ and $N$ is the number parallel subconductors in the pole. As it is proposed at [14], a cost model to estimate the total investment cost of the line (structures and conductors) is

$$
C=a+b V+S(c N+d) \times L[M U S D]
$$

where, $\quad \mathrm{a}=69.95[\mathrm{USD} / \mathrm{km}], \quad \mathrm{b}=115.37 \mathrm{USD} /(\mathrm{kV}-\mathrm{km}), \quad \mathrm{c}=1.177 \mathrm{USD} /(\mathrm{km}-\mathrm{mm} 2) \quad$ and $\mathrm{d}=10.25 \mathrm{USD} /$ $(\mathrm{km}-\mathrm{mm} 2)$ are constants obtained by curve fitting of the tower weight and the conductor data [14]. $\mathrm{V}$ is the semipole to ground voltage $(\mathrm{kV})$. With the total cost of the line is then possible to estimate the operation and maintenance (O\&M) costs, which are considered $2 \%$ of the line, cost [17]; although, some authors estimate the maintenance cost in $0.5 \%$ [18].

Finally, adding the cost of the losses, the weighted average cost of capital (WACC) of the project and the lifetime (30 years [18]), it is calculated the annual equivalent cost (AEC-in millions of USD at 2019) that is used to compare all the alternatives, selecting the one with lowest value. The cost of the losses in USD was calculated as:

$$
C_{L}=\left(L_{j}+L_{c}\right) \times L \times 8760 \times f_{L} \times C_{e}[U S D]
$$

where, $L$ is the length of the line in kilometers, $f_{L}$ is the loss factor and $C_{e}$ is the cost of the energy in [USD $/ \mathrm{kW}$ ]. It is important to mention that in order to compare all this costs, it necessary bring all of them to present value by applying the corresponding factors.

\subsection{HVDC underground cable}

Underground HVDC interconnections is a recent solution to environmental constraints for the construction of reserved areas; as it occurred at INELFE in Europe [2, 19]. The considerations for the underground cable are less than the ones for the overhead line. The technical considerations are only the capacity of the cable and the type [1]. There are different types of conductors but not all can work with VSC technology, therefore the type of cable chose is XLPE for using with VSC technology [2, 20]. The economic considerations are based on [21]. The model computes an equivalent length $\left(L_{f}\right)$ given by:

$$
L_{f}=\frac{5}{4} L_{s u b t}
$$

where, $L_{\text {subt }}$ is the length of the HVDC line that is underground. Then, the cost of the HVDC undergrounded link is estimated by [21]:

$$
C_{\text {subt }}=B_{l p} \times L_{f} \times P+B_{l} \times L_{f}+B_{o}[\mathrm{MUSD}]
$$

where, $B_{l p}=0.98\left[\frac{M M €}{(\mathrm{~km})(\mathrm{GW})}\right], B_{l}=0.27\left[\frac{M M €}{\mathrm{~km}}\right], B_{o}=3.63 M M €$ and $P$ is the total line capacity power expressed in GW. The authors of [21] introduces a factor of $125 \%$ the estimated cost of the line for computing the investment cost. This final investment cost contains all the possible unexpected troubles at a project of this kind.

For this case the losses costs are considered as a part of the operational costs which is define as $2.2 \%$ [22]. From all this data and having a lifetime of 30 years is possible to find the EAC for the underground line. Same as the overhead line, it is necessary to bring all the costs to present value for a valid comparing.

\subsection{Cost of VSC converter stations}

Because there is still a considerable uncertainty about the rigor of cost estimation models of VSC converter stations, the proposed methodology takes two different existing models and compares the results, the first is from [21] and second one is from [23]. Beyond that, it was done an extensive research about 
models to estimate the costs of VSC stations giving some interesting results that will be shared in the next sections. The most complete models for the stations have to constants: the first one is a slope that gives the variable cost of increasing the stations power capacity and the second one is a fixed cost of creating a station.

$$
\begin{aligned}
& C_{V S C S}=112.99 \times P_{T}+23.5[\mathrm{MUSD}] \\
& C_{V S C S}=0.083 \times P_{T}+28[\mathrm{MUSD}]
\end{aligned}
$$

The power $\left(P_{T}\right)$ at $(9)$ an (10) is given in GW. It is very interesting to see that these models have very similar constants; an even though they vary in a few millions, is easy to see that there is a good correlation between them. For the stations is also necessary to calculate the operating and maintenance costs $(\mathrm{O} \& \mathrm{M})$ and the losses costs. After doing these, the AEC is calculated. All the costs are brought to present value to make a valid comparison.

\subsection{Methodology algorithm}

Figure 1 presents the resume of the proposed methodology of this paper. As it can be seen it has two main paths, one corresponding to methodology for the overhead line and the other one corresponding to everything related to the underground cable. At the end both paths converge at calculating the stations costs which are the same for both types of interconnection. Finally, it ends by doing a verification of the technical model through simulation.

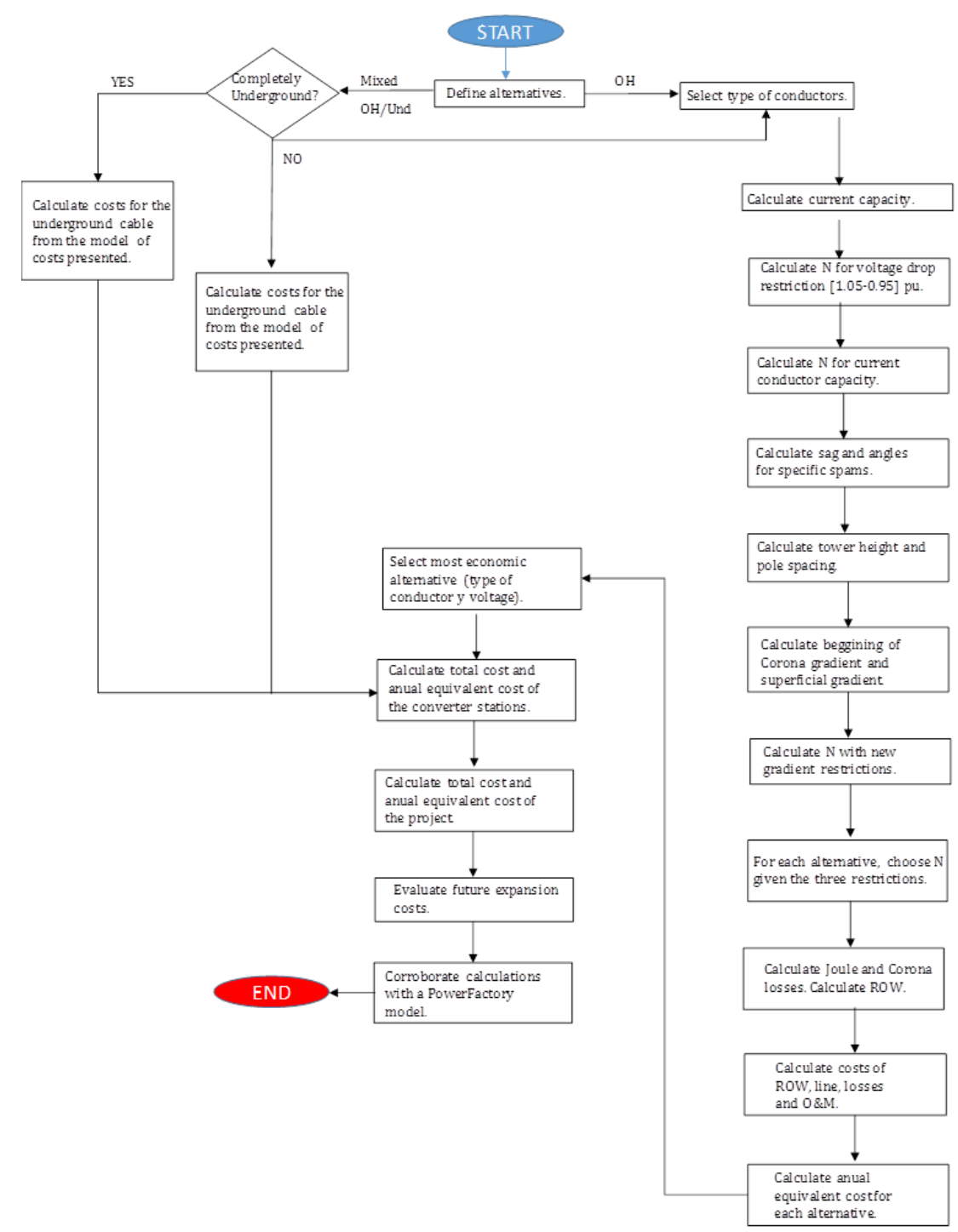

Figure 1. Methodology algorithm for evaluating the viability of the interconnection 


\section{RESULTS AND ANALYSIS}

\subsection{Case of study: Moyabamba-Iquitos interconnection}

Since 2010, and even before, the interconnection between Moyobamba and Iquitos (Peru) has existed as a thought, but due to multiple reasons including political, social, environmental and economic problems it has not been able to be materialized. Iquitos, with its population of almost 500 thousand people, is considered a small city, but not negligible. The peak demand in 2014 was about $55 \mathrm{MW}$, but this is expected to increase between $3.5 \%$ and $7.6 \%$ yearly, potentially reaching more than $200 \mathrm{MW}$ in the next 20 years. An old thermoelectric supply the actual demand of Iquitos, and even though, the new thermoelectric project of about $70 \mathrm{MW}$ does not seem to fix the long-term problem, especially in a world that is going towards decarbonation. As an addition to this, a new hydroelectric central of $550 \mathrm{MW}$ in being considered near Iquitos, this would make the construction of the line not an option but a necessity. In South America, there are other formulated HVDC projects with similar characteristics; like Colombia-Panama interconnection (around $650 \mathrm{~km}, 300 \mathrm{MW}$ ) [24].

The AC project, a $220 \mathrm{kV}$ line of about 631 kilometers, was budgeted in more than 500 million USD, an even though it was approved and signed in 2014, it was then cancelled for a violation of the contract and some other political reasons. Thanks to this, it has been possible to rethink the problem an offer the region a more economical and less environmentally harmful solution.

\subsection{Alternatives of interconnection in HVDC}

Five alternatives in HVDC where considered to solve this problem. All of them considering a power transport capacity of $200 \mathrm{MW}$. At Table 1, main alternatives are shown; these alternatives go from a $100 \%$ overhead line to a $100 \%$ underground line with variations of $25 \%$. This means that a sensibility study is being made to choose the best proportion of the sections. For the cases where there was a section of overhead line, the following possibilities were considered for the tension of the system as shown in Table 2.

Table 1. Alternatives evaluated for the interconnection

\begin{tabular}{ccc}
\hline Alternative & \%Underground & \%Overhead \\
\hline 1 & 0 & 100 \\
2 & 25 & 75 \\
3 & 50 & 50 \\
4 & 75 & 25 \\
5 & 100 & 0 \\
\hline
\end{tabular}

Table 2. Voltage options for the overhead sections

\begin{tabular}{cccc}
\hline Alternative & $\begin{array}{c}+ \text { /- Semipole } \\
\text { Voltage }(\mathrm{kV})\end{array}$ & $\begin{array}{c}\text { Current per } \\
\text { Semipole }(\mathrm{kA})\end{array}$ & Span $(\mathrm{m})$ \\
\hline 1 & 50 & 2.00 & 300 \\
2 & 75 & 1.33 & 300 \\
3 & 100 & 1.00 & 300 \\
4 & 125 & 0.80 & 300 \\
5 & 150 & 0.67 & 300 \\
6 & 175 & 0.57 & 300 \\
7 & 200 & 0.50 & 400 \\
8 & 225 & 0.44 & 400 \\
9 & 250 & 0.40 & 400 \\
10 & 275 & 0.36 & 400 \\
11 & 300 & 0.33 & 400 \\
12 & 325 & 0.31 & 400 \\
13 & 350 & 0.29 & 400 \\
14 & 375 & 0.27 & 400 \\
\hline
\end{tabular}

\subsection{Results-overhead line sections}

When applying the methodology, the first result obtained is the current capacity of each conductor. By recommendations of [14], the operational temperature is set at $60^{\circ} \mathrm{C}$, which is considered a healthy temperature for the cable. The equations describing the thermal behavior of the conductor are described at [16]. After doing the calculation, values on Table 3 are obtained.

With this capacity is possible to calculate the number of conductors needed for each type. Then this number is restricted by the second constraint that is the surface gradient for the Corona effect. As it is clear in Figure $2,+/-375 \mathrm{kV}$ is the voltage at which is no longer allowed for any type of conductor to have $\mathrm{N}=1$. 
Table 3. Current capacity at different operational temperatures

\begin{tabular}{ccccc}
\hline ACSR Code & Capacity at $50^{\circ} \mathrm{C}(\mathrm{A})$ & Capacity at $60^{\circ} \mathrm{C}(\mathrm{A})$ & Capacity at $70^{\circ} \mathrm{C}(\mathrm{A})$ & $\mathrm{Capacity}$ at $90^{\circ} \mathrm{C}(\mathrm{A})$ \\
\hline Joree & 937.35 & 1298.87 & 1567.22 & 1974.40 \\
Thrasher & 886.01 & 1225.84 & 1478.28 & 1861.41 \\
Kiwi & 846.93 & 1170.20 & 1410.51 & 1775.30 \\
Chukar & 729.54 & 1005.16 & 1210.32 & 1521.91 \\
Lapwing & 690.13 & 948.71 & 1141.42 & 1434.19 \\
Bobolink & 643.50 & 883.05 & 1061.74 & 1333.28 \\
Dipper & 622.75 & 854.51 & 1027.40 & 1290.12 \\
Bittern & 592.60 & 811.58 & 975.09 & 1223.65 \\
Bluejay & 542.79 & 741.73 & 890.43 & 1116.57 \\
Rail & 489.35 & 667.02 & 799.99 & 1002.29 \\
Tern & 433.30 & 588.89 & 705.51 & 885.95 \\
Crow & 406.56 & 552.06 & 661.26 & 833.06 \\
Gull & 387.62 & 526.54 & 632.77 & 796.44 \\
Goose & 376.32 & 512.26 & 615.19 & 773.84 \\
Duck & 365.79 & 497.04 & 596.51 & 749.87 \\
Eagle & 350.27 & 475.94 & 571.19 & 718.05 \\
Heron & 329.83 & 446.57 & 535.20 & 671.94 \\
Hen & 320.86 & 433.62 & 519.32 & 651.58 \\
Lark & 289.16 & 388.51 & 464.24 & 581.22 \\
\hline
\end{tabular}

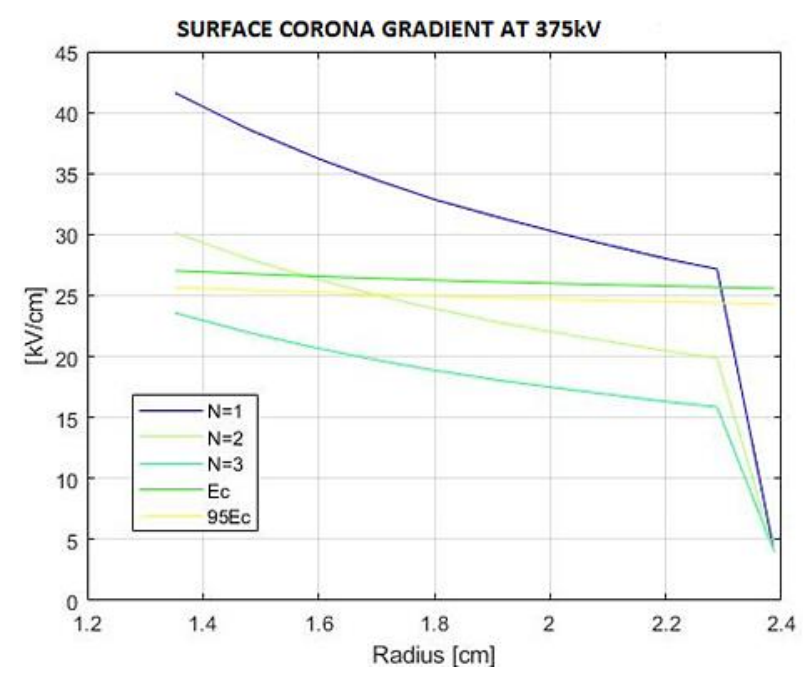

Figure 2. Voltage limit for $\mathrm{N}=1$ by gradient restriction

The third constraint for the number of conductors is obtained by setting the operational voltage limits at 1.05 and 0.95 at both ends. With this boundaries, it is possible to calculate the minimum number of parallel conductors (or resistance) needed to satisfy these maximum voltage drop. At this point, it became evident that the conductors with less gauge were not feasible for the solution because they have a high resistance. This means that even though they satisfy the current capacity, the voltage drop is so elevated that it is not viable. For example, with $+/-50 \mathrm{kV}$ Lark conductor needs more than 30 parallel conductors to satisfy the voltage drop requirement, with higher voltage, this is less critical, but it remains as a problem. After calculating the voltage drop for each alternative (voltage and type of conductor), the final $\mathrm{N}$ for each alternative was calculated as the maximum of the $\mathrm{N}$ for all three restrictions. Once having this number, it was time to calculate the height, the pole spacing, the row and the costs.

The best alternative for the overhead sections resulted to be the one with $250 \mathrm{kV}$ at each semipole with the conductor named Joree. This conductor is the one with the largest gauge, which means it is also the one with less resistance and therefore less joule losses (much significant than corona losses). The results for the overhead line are presented with the rest of the alternatives in section 3.5.

\subsection{Results-cost of VSC converter stations}

As it was expected, the results for the two different models are substantially the same. Given the fact that the uncertainties are high, seven million dollars (5\%), which the difference of the costs between the two models, is considered inside the range of tolerance. Table 4 provides a complete economic analysis for the evaluation of the stations AEC. 
Table 4. Economic analysis for VSC converter stations

\begin{tabular}{ccc}
\hline Parameter & Cost Model (9) & Cost Model (10) \\
\hline Contractual cost-MMUSD 2019 & 112.18 & - \\
Investment cost-MMUSD 2019 & 140.23 & 133.35 \\
Power losses-MW & 2.80 & 2.80 \\
Cost of power losses-MM USD 2019 & 5.15 & 5.15 \\
O\&M-MMUSD 2019 & 0.70 & 0.67 \\
STATIONS AEC-MMUSD 2019 & 17.41 & 16.55 \\
Total AEC-MMUSD 2019 & 23.26 & 22.37 \\
\hline
\end{tabular}

To see how close these models are from other references, an extensive research was made. The findings are interesting. Since around the year 2000 a linear model has been used to estimate the cost of the VSC stations. This slope, depending on the reference is somewhere between 0.15 and $0.20 \mathrm{MUSD} / \mathrm{MW}$. With these slopes, the cost would be lower than the ones presented, but it is because these slopes are just considering the variable cost of the stations while omitting the fixed cost of building it. If compared, the results with these slopes would be very similar to the ones obtained by erasing the fixed component from the models.

\subsection{Results-mixed alternatives}

At Table 5 the total investment cost and the total AEC is resumed in order to be compared with the cost of the previous AC alternative. The power transfer cost calculated as the cost per km divided into the transferred power, as defined at [25], is between 1793 USD\$/MW.km and 5585 USD\$\$/MW.km; in the range computed by [25]. The results are obvious. The underground cable is much more expensive than the overhead line mainly because of the cable. Although the alternatives become more expensive while increasing the percentage of underground section, even with $75 \%$ percent of it underground it results cheaper than the AC alternative, which costs 627 MMUSD2019. This means that many of the environmental problems can be resolved by using a $75 \%$ percent underground interconnection without spending more than it was originally stipulated. On the other hand, the savings by doing the first alternative are enormous given the fact that the overhead line structure and cables are economic. At the first alternative, more than the half of the investment is for covering the costs of the stations. Given these results, maybe the best alternative to be considered is one in between (maybe the second depending on the necessities) where the line is mainly overhead but at high biodiversity areas it becomes underground in order to the reduce the impact on the environment.

Table 5. Economic results for mixed alternatives

\begin{tabular}{ccccc}
\hline \multirow{2}{*}{ Alternative } & \multicolumn{2}{c}{ Total Investment Cost-MMUSD 2019 } & \multicolumn{2}{c}{ Total AEC cost-MMUSD 2019 } \\
& Cost Model (9) & Cost Model (10) & Cost Model (9) & Cost Model (10) \\
\hline 1 & 226.28 & 219.40 & 34.38 & 33.49 \\
2 & 383.27 & 376.39 & 56.74 & 55.85 \\
3 & 533.47 & 526.59 & 78.10 & 77.21 \\
4 & 586.55 & 579.67 & 85.27 & 84.39 \\
5 & 704.81 & 697.93 & 101.97 & 101.08 \\
\hline
\end{tabular}

Once it was defined the type of conductors and the voltage of the possible line, it was possible to estimate the maximum transport capacity of the line considering a future expansion of the converter stations. With the voltage and the conductors selected, the actual line can carry up to $625 \mathrm{MW}$, more than three times the design capacity (considering an operational temperature of $60^{\circ} \mathrm{C}$ ). The line could carry more than $800 \mathrm{MW}$ and as the voltage is intended to remain constant, there is no problem with surface gradient of the Corona effect.

\subsection{Verification through simulation analysis of the symmetrical monopole}

With the model at Figure 3, the details such as more precise losses and characteristics of the converter stations were stablished. These losses were compared to the calculations made in the previous sections and the results were positives. The only difference found was because in order to take $200 \mathrm{MW}$ to Iquitos there has to be $200 \mathrm{MW}$ plus some additional MW that are going to be loss somewhere in between. This means that the real current through the line is a little bit higher than the one calculated theoretically, but this difference is just about $4 \%$. 


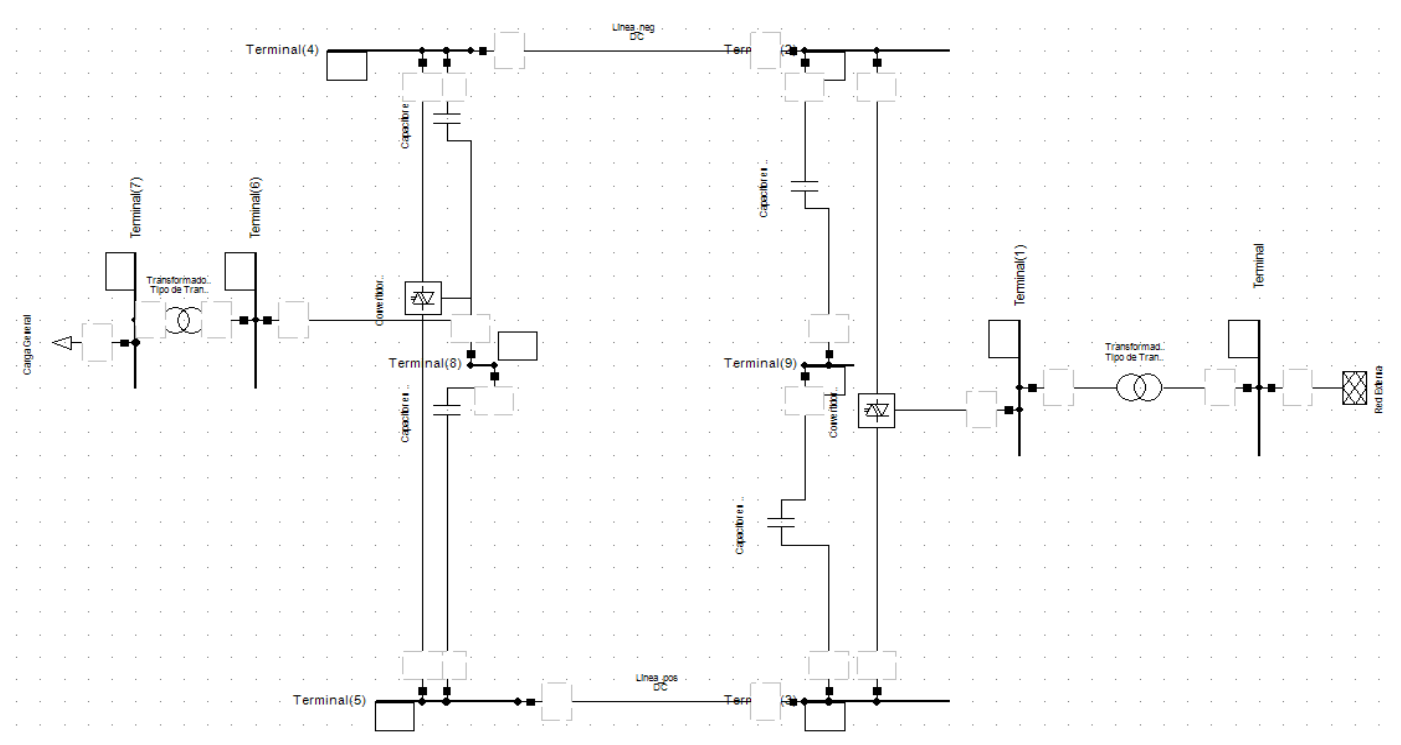

Figure 3. Model of the moyobamba-iquitos interconnection

\section{CONCLUSION}

This paper has proposed a methodology that allows the evaluation of viability, technically and economically of HDVC-VSC interconnection projects for great distance and high demand considering overhead and/or underground DC line. The methodology has been applied to a real interconnection problem in Peru showing its advantages for real applications. In conclusion, it is possible to say that there are at least four viable HVDC alternatives for the Moyobamba interconnection, technically and economically, when compared to the HVAC solution. With the HVDC interconnection is possible to solve economic and environmental problems, which are the main causes of the social and political debates around the matter. It is also possible to conclude that rethinking the path of the line might be a good idea considering that an underground cable can be used to go through delicate areas. Between Moyobamba and Iquitos there are $480 \mathrm{~km}$ in straight line, but the interconnection has almost $150 \mathrm{~km}$ more than that, if the path is change it can be reduce in several kilometers, which would be beneficial to everyone probably saving millions of USD. Finally, the line design for $200 \mathrm{MW}$ can carry up to $625 \mathrm{MW}$ just by expanding the converter stations, this is a huge advantage considering the possible needs of the city. In general, an interconnection for this type of isolated areas (long distance, hard terrain, no negligible demand) is more feasible compared to any other existing alternative.

As a future work, it may result necessary to study the ceraunic level of the region in order to the estimate the reliability parameters of the line. Given the fact that it is a symmetric monopole, any permanent fault would cause a complete outage of the line, so it is important to know the probabilities of such events to happen. Other future works are related to the detail engineering such as calculating the proper grounding for the converter stations and the towers, the guard cable, the possible transition station for going from overhead to underground and vice versa. It might also be helpful to the estimate the real impact of and underground cable in a delicate ecosystem such as the amazon rain forest.

\section{REFERENCES}

[1] T. Van Hertem, et al., "HVDC Grids for Offshore and Supergrid of the Future," New Jersey, John Wiley \& Sons, 2016.

[2] A. Alassi, et al., "HVDC Transmission: Technology Review, Market Trends and Future Outlook," Renewable and Sustainable Energy Reviews, vol. 112, pp. 530-554, 2019.

[3] M. A. Elizondo, et al., "Interarea Oscillation Damping Control Using High-Voltage DC Transmission: A Survey," in IEEE Transactions on Power Systems, vol. 33, no. 6, pp. 6915-6923, 2018.

[4] J. Sun, et al., "Renewable Energy Transmission by HVDC across the Continent: System Challenges and Opportunities," CSEE Journal of Power and Energy Systems, vol. 3 no. 4, pp. 353-364, 2017.

[5] F. A. Acero and M. A. Rios, "Planning MTDC Grids based Graphs Theory," International Journal of Electrical and Computer Engineering (IJECE), vol. 11, no. 1, pp. 37-46, 2021.

[6] F. Z. El-Mazouri, et al., "Application of the ELECTRE III Method at the Moroccan Rural Electrification Program," International Journal of Electrical and Computer Engineering (IJECE), vol. 8, no. 5, pp. 3285-3295, 2018. 
[7] I. Rozic, et al., "The energy sustainability of the small agricultural farms isolated of electric power grid," International Review of Electrical Engineering (IREE), vol. 13, no. 3, pp. 229-236, 2018.

[8] E. Banguero, et al., "Renewable microgrid operational results and economic evaluation using RETScreen," International Journal of Electrical and Computer Engineering (IJECE), vol. 9, no. 2, pp. 723-731, 2019.

[9] M. Asaduz-Zaman, et al., "Coordinated Control of Interconnected Microgrid and Energy Storage System," International Journal of Electrical and Computer Engineering (IJECE), vol. 8, no. 6, pp. 4781-4789, 2018.

[10] T. G. Magg, et al., "Caprivi Link HVDC Interconnector: comparison between energized system testing and real time simulator testing," in Proceedings of CIGRE Session 2012, Paper B4 107, 2012.

[11] M. Y. Suliman, "Active and reactive power flow management in parallel transmission lines using static series compensation (SSC) with energy storage," International Journal of Electrical and Computer Engineering (IJECE), vol. 9, no. 6, pp. 4598-4609, 2019.

[12] Cesel Ingenieros, "Technical viability studies for the construction of the transmission line MoyobambaYutimaguas-Nauta-Iquitos at 220kV (In Spanish)," Second report: descriptive memory s.1., Private Investment Promotion Agency, 2012.

[13] Proinversión, "Concession of the project: Moyobamba-Iquitos transmission line at $220 \mathrm{kV}$ and associated substations (In Spanish)," Final presentation, 2014.

[14] CIGRE Joint Working Group B2/B4/C1.17, "Brochure 388: Impacts of HVDC lines on the economics of HVDC projects," Paris: CIGRÉ, 2009.

[15] CIGRE Join Working Group B2/B4/C1.17, "Recommended Voltages for HVDC Grids,” Paris: CIGRE, 2017.

[16] CIGRE Joint Working Group 22.12, "Brochure 207: Thermal behaviour of overhead conductors," Paris: CIGRÉ, 2002.

[17] D. Parra, "Tension level optimization for the interconnection between Colectora 2 and Cerromatoso through a HVDC-VSC link (In Spanish),” Bogotá. Electrical Engineering Thesis, Universidad de los Andes, 2018.

[18] A. Raza, et al., "Economic analysis for HVDC transmission system in Pakistan," International Journal of Control and Automation (IJCA), vol. 10, no. 11, pp. 29-38, 2017.

[19] L. Coronado, et al., "INELFE: main description and operational experience over three years in service," in Proceedings of 2019 AEIT HVDC International Conference, Florence, Italy, 2019.

[20] N. MacLeod, et al., "The design and development of a 2000MW HVDC interconnector between Great Britain and France," in Proceedings of 15th IET International Conference on AC and DC Power Transmission (ACDC 2019), Coventry, UK, 2019.

[21] T. Vrana and P. Härtel, "Estimation of investment model cost parameters for VSC HVDC transmission infrastructure," Electric Power Systems Research, vol. 160, pp. 99-108, 2018.

[22] D. Paez and M. A. Rios, "Cost Analysis of an MTDC for interconnection Guajira-Cerromatoso-Panama," in Proceedings of FISE/IEEE-CIGRE 2019, Medellin, Colombia, 2019.

[23] A. L'Abbate, "Draft deliverable d3.3.2. Review of cost of transmission of infrastructures, including crossborder connections," in Realise Grid, pp. 16-19, 2011.

[24] D. Velasco, et al., "Power transmission in direct current. Future expectations for Colombia," Renewable and Sustainable Energy Reviews, vol. 15, no. 1, pp. 759-765, 2011.

[25] M. E. Elgeziry, et al., "Integration Enhancement of Grid-Connected Wind Farms Using HVDC Systems: Egyptian Network Case Study," in Proceedings of 2019 21st International Middle East Power Systems Conference (MEPCON), Egypt, 2019.

\section{BIOGRAPHIES OF AUTHORS}

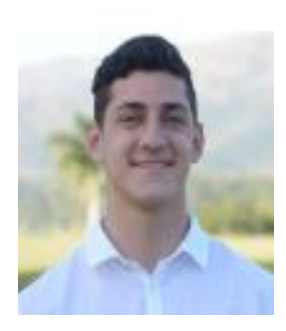

Juan Andrés Varela received a degree in electrical engineering in 2020 from Universidad de los Andes, Bogota. Colombia. He joined USAENE has consultant engineer for transmission and generation studies and design. Then, he joined ISA (Interconexión Eléctrica S.A.).

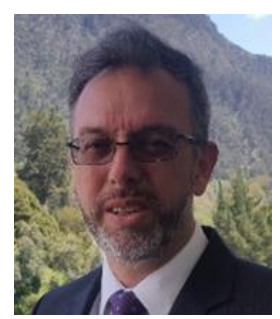

Mario Alberto Ríos received a degree in electrical engineering in 1991 and a M.Sc. Degree in electrical engineering in 1992, both from Universidad de los Andes, Bogotá, Colombia. He received a Ph.D. degree in electrical engineering from INPG-LEG, Grenoble, France, in 1998, and a Doctoral degree in engineering from Universidad de los Andes, in 1998. He worked as a consultant engineer in ConCol (now WSP), Bogotá, Colombia, during 12 years. Also, he was a Research Associate at the University of Manchester (formerly, UMIST). Currently, he is Full Professor at the Department of Electrical Engineering, School of Engineering, Universidad de los Andes, Bogotá, and director of the Power and Energy Research Group of this university. 